\title{
Religião sem Deus: liberdade religiosa em Ronald Dworkin
}

\author{
Religion without God: Dworkin's approach \\ of religious freedom
}

\author{
Dilson Cavalcanti Batista Neto ${ }^{1}$ \\ José Antonio Remédio ${ }^{2}$
}

Resumo: A pesquisa tem por objeto analisar criticamente a concepção de liberdade religiosa de Ronald Dworkin, com foco em sua obra Religion Without God. Dworkin trata a liberdação dworkniana; no último tópico, contrapõe o Religion Without God com uma abordagem de John Rawls. O método utilizado é o dedutivo, com base em pesquisa bibliográfica, dou-

1 Doutor em Direito pela Pontifícia Universidade Católica de São Paulo, Núcleo de Filosofia do Direito. Mestre em Direito pela Universidade Federal da Bahia, Linha de Pesquisa "Limites do Discurso Jurídico". Graduado em Direito pela Universidade Federal de Sergipe. Atualmente é professor de dedicação exclusiva no Centro Universitário Adventista de São Paulo, campus Engenheiro Coelho. Currículo Lattes: http://lattes. cnpq.br/7065501475340449

2 Pós-doutor em Direito pela Universidade Estadual do Norte do Paraná UENP (2019). Doutorado em Direito do Estado pela Pontifícia Universidade Católica de São Paulo - PUCSP (2006). Mestre em Direito do Estado pela Universidade Metodista de Piracicaba - UNIMEP (2000). Promotor de Justiça do Ministério Público do Estado de São Paulo aposentado. Advogado e Consultor Jurídico. Professor de Graduação em Direito do UNASP e Graduação e Pós-graduação (Mestrado) em Direito da UNIMEP. 
trinária e legislativa. Conclui-se que a concepção de liberdade religiosa que é objeto da obra Religion Without God, de Ronald Dworkin, embora abrangente, inclusive tendo como seus titularesde religiosa como direito à independência ética, o que inclui ateus e agnósticos. Apesar do mérito de sua proposição, a visão do autor é insuficiente para explicar e justificar de forma segura o tema da liberdade religiosa no âmbito de uma democracia. A pesquisa é dividida em quatro tópicos: inicia-se com a apresentação dos elementos centrais da proposta de Dworkin sobre liberdade religiosa; num segundo momento, indica as virtudes de sua abordagem abrangente e inclusivista; no terceiro tópico, propõe uma ressalva, apontando possíveis inconsistências da concep ateus e agnósticos, é insuficiente para a devida proteção de todas as expressões religiosas no âmbito de uma democracia.

Palavras-chave: Liberdade Religiosa em Dworkin. Religião e Democracia. Religião sem Deus.

Abstract: The research aims to critically analyze the conception of religious freedom from Ronald Dworkin, focused on his work called Religion Without God. Dworkin treats religious freedom as a right to ethical independence, which includes atheists and agnostics. Despite the merits of his proposal, the author's view is insufficient to explain and safely justify the issue of religious freedom in the context of a democracy. The research is divided into four topics: begins with the presentation of the core elements of Dworkin's proposal on religious freedom; subsequently, it indicates the virtues of its comprehensive and inclusivist approach; in the third topic, proposes a caveat pointing out possible inconsistencies of the Dworkin's conception; in the last topic, contrasts Religion Without God with 
an approach by John Rawls. The method used is the deductive, based on bibliographical, doctrinal and legislative research. It concludes that Ronald Dworkin's conception of religious freedom, while comprehensive, including its atheists and agnostics, is insufficient for the proper protection of all religious expressions within a democracy.

Keywords: Dworkin's approach of religious freedom. Religion and Democracy. Religion without God.

\section{INTRODUÇÃO}

A liberdade religiosa, no entendimento de Ronald Dworkin, não é um direito que tem como titular somente os que pertencem às religiões tradicionalmente reconhecidas, mas decorre de um direito geral de liberdade de consciência, tida como independência ética. Qualquer cidadão, inclusive os ateus, agnósticos e deístas, são titulares de tal direito. Enquanto as expressões religiosas estiverem ligadas ao direito geral de liberdade de consciência, o autor entende que possuem um status de prioridade em relação a outros direitos fundamentais, por proporem um modelo liberal de sociedade. Ou seja, para que se proíba uma expressão religiosa é preciso uma forte carga argumentativa indicando o ataque a um ou mais direitos fundamentais.

Todavia, quando não houver uma interação direta entre liberdade de religião e de consciência, como quando religiões exigem o uso de entorpecentes em seus rituais, tais práticas não possuem um status especial, podendo ser reprimidas através de argumentos mais simples, como, por exemplo, por serem contrárias ao direito à saúde.

Esta concepção de liberdade religiosa está inserida em diversas obras do autor ${ }^{3}$, como quando trata da questão

3 DWORKIN, 1993. 
da tutela do direito à vida em detrimento dos argumentos religiosos em Life's Dominion ${ }^{4}$. Em 2006, analisa a questão da religião no embate democrático em Is Democracy Possible Here ${ }^{5}$ De forma reduzida e mais direta ${ }^{6}$, o tema é retomado em Justice for Hedgehogs ${ }^{7}$. Mas foi em Religion Without God que o autor conseguiu expor com mais detalhes sua visão sobre a liberdade religiosa, ao tratar de uma série de palestras inspiradas na visão religiosa de Albert Einstein, proferida na Universidade de Berna. Porém, por conta do seu falecimento, não houve tempo para Dworkin dar maiores explicações e esclarecimentos sobre sua visão em relação ao assunto.

Apesar de sustentável em diversos pontos, a visão de Dworkin de que a religião não possui um status especial, como possui a liberdade de consciência, pode abrir espaço para limitações indevidas da expressão, em especial de religiões mais tradicionais, que moldaram sobremaneira a cultura ocidental. Um conceito muito amplo de religião coloca o Estado em dificuldade, inclusive para definir quais grupos poderão ter imunidade fiscal, ou serem contemplados com dinheiro público, entre outros aspectos.

Não se pode desconsiderar que a estrutura política do Estado Moderno, enquanto centro decisório e de mando, está alicerçada em variadas relações com outras esferas de poder social, sendo que "uma das ligações complexas do Estado

4 Em português foi traduzido pela editora Martins Fontes como “Domínio da Vida: Aborto, Eutanásia e Liberdades Individuais” (DWORKIN, 2009). A discussão encontra-se em especial em seu Capítulo 3.

5 DWORKIN, 2006.

6 DWORKIN, 2011.

7 Em português o título é "A Raposa e o Porco Espinho: Justiça e Valor" (DWORKIN 2014). Esta concepção de liberdade religiosa se encontra no Capítulo 17 da referida obra.

8 DWORKIN, 2013. 
com outras esferas de poder social é a ligação estabelecida com o poder religioso" ${ }^{\prime \prime}$.

Na sociedade contemporânea, as formas de transmissão de conhecimentos religiosos "passaram a ter novo e necessário enquadramento jurídico constitucional em decorrência de seu notório impacto e relevância" expressivo número de pessoas. ${ }^{10}$

Nesse contexto, a pesquisa tem como objetivo apresentar a visão de Ronald Dworkin sobre a liberdade religiosa, num primeiro momento, para então apresentar seus pontos positivos e problemáticos.

Estruturalmente, a pesquisa está distribuída em quatro partes: inicialmente, para efeito de contextualização, apresentam-se os pontos básicos que levam Dworkin à sua perspectiva de liberdade religiosa; em seguida, apontam-se as virtudes de sua abordagem abrangente e inclusivista; na sequência, formula-se uma ressalva a tal compreensão ${ }^{11}$; por fim, busca-se demonstrar que as críticas ao pensamento de Dworkin podem ser feitas também por perspectivas liberais, como a de John Rawls.

O método utilizado é o dedutivo, com base em pesquisa bibliográfica e doutrinária. Tem-se, como hipótese, que a

9 BORGES; ALVES, 2013, p. 228.

10 FIORILLO; FERREIRA, 2018, p. 40.

11 A escolha do termo ressalva é intencional, pois não se trata de uma objeção minuciosa, mas de uma preocupação que permeia o presente trabalho, ou seja, a de garantir que o religioso tenha uma status pleno de cidadão, no sentido de evitar que esta visão abrangente da liberdade religiosa não possa legitimar uma irrazoável criminalização do discurso religioso, em especial aos ligados à interpretação dos textos religiosos. A natureza de uma crítica à perspectiva do direito à liberdade religiosa de Dworkin parece sugerir uma crítica ao seu conceito de direito como um todo. Em especial, uma possível interpretação da ressalva que se faz aqui é que se parte de elementos jusnaturalistas/comunitaristas contra a visão de direito enquanto integridade de Dworkin. 
concepção de liberdade religiosa constante da obra Religião Sem Deus, de Ronald Dworkin, embora seja abrangente e inclusivista, é insuficiente para explicar diversas questões sobre o tema da religião no âmbito de uma democracia.

\section{CONCEITO DE LIBERDADE RELIGIOSA EM RELIGION WITHOUT GOD}

Dworkin inicia a obra Religion Without God com a construção de um conceito curioso de ateísmo religioso (religious atheism). O que parece ser algo contraditório, ganha significado quando se busca uma definição mais ampla do que seria a ideia de religião descolada de divindades ou entidades metafísicas (espíritos da natureza, antepassados etc.), que sejam objeto de culto. A ideia de religião é mais ampla do que as religiões teístas, configurando-se uma atitude religiosa (religious attitude) que abarca tanto o teísmo, o deísmo (ambos comumente inseridos nas descrições sobre religião) e o ateísmo religioso.

O que uniria todas as religiões seria o fato de que elas deveriam aceitar dois valores como objetivamente verdadeiros ${ }^{12}$. O primeiro é chamado de "o propósito intrínseco à vida" (life's intrinsic meaning), que aponta que a vida humana tem significado ou importância objetiva. Isso quer dizer que a atitude religiosa pressupõe que cada ser humano tem a responsabilidade inevitável e inata de tornar sua vida bem-sucedida, assumindo responsabilidades éticas. $\mathrm{O}$ segundo valor é denominado de "beleza intrínseca à natureza" (nature's intrinsic beauty), para o qual a natureza, que inclui todo o Universo e suas partes, não é simplesmente uma questão fática, material, mas possui um valor intrínseco, algo de maravilhoso (wonder) e de sublime.

12 DWORKIN, 2013, p. 10. 
A compreensão abrangente de religião como atitude religiosa não é tão larga a ponto de incluir o naturalismo materialista, já que este não aceita o segundo valor, no caso a beleza intrínseca à natureza, visto que só reconhece como verdade aquilo que pode ser estudado pelas ciências naturais, não se encaixando a ideia de valores objetivos. De igual forma não se encaixa num realismo, que busca resumir toda ideia de afeto e percepção do caráter sublime da natureza pela mera reação química do corpo enquanto objeto da biologia $^{13}$.

O que separaria o teísmo do ateísmo religioso é que o primeiro iria além dos dois valores antes mencionados, acrescentando elementos e obrigações ligadas a cultos e rituais ${ }^{14}$. Como exemplos de um ateu religioso, são trazidos relatos em que Einstein aponta uma fé na beleza da natureza e na existência de valores objetivos transcendentes, o que se pode inferir, por toda sua obra, é também a posição do próprio Dworkin ${ }^{15}$.

O teísmo, por sua vez, gera comprometimentos relacionados à existência de uma divindade. As religiões realizam seus rituais através do pressuposto de tal existência. Por isso, Dworkin afirma que o teísmo possui um elemento chamado "parte científica das religiões convencionais". Com isso, não quer afirmar que as religiões são cientificistas, mas simplesmente que só fará sentido cultuar um deus que se acredite existir. Portanto, para Dworkin, os valores ligados ao culto dependem dessa necessidade que as religiões teístas possuem de que seus ritos ganhem sentido ${ }^{16}$. Por outro lado, os ateus religiosos não precisam ingressar no mérito

13 DWORKIN, 2013, p. 12-13.

14 DWORKIN, 2013, p. 11.

15 DWORKIN, 2013, p. 6.

16 DWORKIN, 2013, p. 24-25. 
da existência ou não de qualquer divindade para terem fé na existência dos dois valores anteriormente citados. ${ }^{17}$

Ateus e teístas religiosos têm em comum a atitude religiosa, não sendo relevante para tal atitude a existência de um deus, segundo Dworkin. Daí a escolha do título Religion Without God. Ambas as visões de religião são protegidas por um princípio mais geral que Dworkin chama de independência ética. Esta, juntamente com o princípio de respeito à própria vida, são determinantes para o conceito de dignidade humana ${ }^{18}$. Para a proteção da dignidade é que se fala em direito de liberdade de consciência e mesmo de liberdade religiosa.

$\mathrm{O}$ direito geral de consciência ligado à independência ética protege todas as atitudes religiosas, quer aponte para um teísmo, deísmo ou ateísmo religioso. Mesmo as religiões tradicionais têm raízes neste direito geral. Nesse sentido, não deve haver por parte de qualquer ente estatal a determinação de que uma fé religiosa é superior às demais. Inclusive, Dworkin enfatiza que o Estado não pode propagar a visão puramente ateísta, ainda que de forma sutil, como a visão mais adequada, pois acabaria impondo uma cosmovisão aos cidadãos ${ }^{19}$. Para comprovar esta visão abrangente de religião, Dworkin cita diversos casos que demonstram como a Suprema Corte dos EUA prefere um conceito mais aberto e independente de divindade ${ }^{20}$.

O ponto polêmico começa quando Dworkin compara a liberdade religiosa na perspectiva da independência ética com a liberdade religiosa em relação a ritos, que dependem da antes citada "parte científica" das religiões. Como visto, a

17 DWORKIN, 2013, p. 25.

18 DWORKIN, 2014, p. 311.

19 DWORKIN, 2013, p. 134.

20 MACEDO JÚNIOR, 2017. 
liberdade religiosa, assim como a de consciência, possui um status especial no sentido de que não pode ser limitada por qualquer motivo, a não ser que se esteja falando na limitação de liberdades de outrem. O que resta saber é se a parte das religiões teístas, que possuem elementos de culto, teriam a mesma prioridade.

Dworkin inicia o argumento apontando que, ao limitar uma religião, o ente estatal não pode simplesmente argumentar que a religião é falsa, pois entraria na seara da ciência da religião, no sentido de que é impossível demonstrar a realidade, ou não, dos deuses. Limitações nesta perspectiva seriam injustas por insultarem a dignidade dos religiosos ${ }^{21}$. Por outro lado, as limitações que podem ocorrer de forma legítima se dão quando a religião acaba atacando algum valor da dignidade de outrem. Como exemplo, aponta que é totalmente plausível, sem maior necessidade de justificativas, que se proíba uma religião de praticar algum rito que sacrifique crianças.

O exemplo hipotético demonstra uma fórmula básica que permeia o argumento de Dworkin: o cerne da liberdade religiosa está em sua expressão naquilo que se iguale com a liberdade de consciência. Por outro lado, expressões de cultos que entrem em colisão com tipos penais ou infrinjam a dignidade humana podem ser limitados sem a necessidade de uma justificativa qualificada. Isto quer dizer que a parte epistêmica e cultural não possui a mesma prioridade em relação ao elemento da crença, que está ligado à consciência, à escolha de valores religiosos que se julgam dignos de serem seguidos.

Estendendo o argumento dworkiniano, caso alguma religião entenda que sua divindade revelou que só se satisfaria com o sacrifício de uma vida humana, este elemento

21 DWORKIN, 2013, p. 113. 
do culto obviamente não poderá ser aceito, pois se trata de uma conduta criminosa. Por outro lado, uma vez limitada a conduta ilícita do culto, não se permitiria que o Estado obrigasse todos os fiéis a se desligarem do grupo, ou mesmo de jurarem contra as crenças sustentadas por ele. Isso porque a porção da religião que possui prioridade é aquela que está ligada ao direito de independência ética ${ }^{22}$.

Tal caso hipotético dá lugar a outros casos reais levantados por Dworkin. Como exemplo, critica algumas decisões relacionadas à lei norte-americana chamada Religious Freedom Restoration Act. Esta entende que a religião é um caso especial quando afirma que "governments should not substantially burden religious exercise without compelling justification" ${ }^{\prime 23}$. Nesse sentido, critica decisões da Suprema Corte, como Gonzales v. Centro Espirita Beneficente União do Vegetal, na qual se permitiu que esta religião, que inclusive é brasileira, pudesse fazer uso do Chá Hoasca (Ayahuasca), que possui efeito alucinógeno, como parte do seu rito. Tal decisão é incoerente, segundo Dworkin, pois cria uma exceção à regulamentação antidroga para as religiões, mas mantém a proibição para qualquer outra doutrina filosófica. Isso seria uma quebra à Primeira Emenda à Constituição dos EUA ${ }^{24}$.

Uma exceção só pode ser admitida em favor de um grupo religioso se restar patente que não haverá prejuízo para os demais grupos, quer sejam religiosos ou não. Como exemplo, Dworkin questiona se um orfanato mantido por instituição religiosa, que não aceite candidatos a adotantes em união homoafetiva, pode receber dinheiro público. Neste caso, a aceitação dessa quebra da igualdade em nome da religião só seria aceitável caso restasse comprovado que

22 DWORKIN, 2013, p. 132.

23 Tradução livre: "os governos não devem trazer um fardo substancial às religiões sem uma justificativa convincente".

24 DWORKIN, 2013, p. 125. 
a postura da instituição não afetaria a oferta de possíveis adotados por casais homoafetivos. Caso o impedimento do orfanato religioso fosse um entrave para a adoção por tal tipo de casal, então a instituição religiosa não seria digna de receber dinheiro público ${ }^{25}$.

Segundo Dworkin, não se pode colocar a religião em um pedestal de intocabilidade, o que é razoável e, por que não dizer, evidente em casos gritantes como o do sacrifício humano ${ }^{26}$. Para Dworkin, voltando ao exemplo das religiões que usam psicotrópicos em seus rituais, quando a Suprema Corte definiu que seriam necessárias maiores justificativas para limitar tal culto além do argumento de que afetariam a dignidade dos membros, acabou criando uma contradição. Qual seria o fundamento, então, para não se abranger a mesma permissão de substâncias da referida religião para que os outros grupos (religiosos ou de matriz filosófica) também possam fazer uso?

Após a breve apresentação da abordagem sobre a prioridade ou não da liberdade religiosa em Dworkin, passa-se a apresentar em que termos pode-se fazer uma ressalva a tal compreensão.

25 DWORKIN, 2013, p. 136.

26 Dworkin está longe de ser o único autor com esta visão. Por exemplo, Brian Leiter, na obra Why Tolerate Religion? (LEITER, 2013), entende que deve haver, sim, respeito pelas religiões. Mas sustenta que estas não gozam de um direito especial, sob pena de se destinar a elas mais que um respeito enquanto reconhecimento, mas se estaria dispensando um respeito afirmativo (affirmative respect), isto é, o ente público passaria a fazer uma avaliação positiva de alguma qualidade de determinada religião, o que ele sustenta ser indevido. 


\section{ELOGIO AO CONCEITO DE LIBERDADE RE- LIGIOSA EM RELIGION WITHOUT GOD}

O primeiro trunfo da abordagem de Religion Without God é sua busca em igualar crentes e não crentes num mesmo patamar, mesmo não tendo sido muito cuidadoso com a escolha da expressão "postura religiosa". Esta perspectiva é muito interessante, em especial quando se trata da proteção da liberdade religiosa individual. Como aponta Jónatas Machado ${ }^{27}$, a melhor jurisprudência para a proteção dos religiosos, constitucionalmente falando, é aquela que considera que a liberdade religiosa não engloba somente as religiões tradicionais, históricas, mas também outras manifestações minoritárias.

A liberdade religiosa nesta perspectiva mais abrangente de religião é oportuna para lidar com a igualdade entre grupos, ou para evitar que se proíba a expressão de grupos minoritários, que é um dos corolários do Estado laico ${ }^{28}$.

Conforme referência de Katya Kozicki e William Soares Pugliese ${ }^{29}$, é ínsita ao pensamento de Dworkin uma concepção liberal de igualdade, no sentido de que a liberdade exige que o governo trate todos os cidadãos com igual consideração e respeito, servindo, inclusive, como premissa da liberdade, na medida em que a distribuição equânime permite o livre desenvolvimento das pessoas.

Um segundo ponto positivo da proposta de Religion Without God é que Dworkin é preciso quando considera que as novas "guerras religiosas" se encontram no âmbito da política $^{30}$, mais especificamente na dificuldade em se chegar a

27 MACHADO, 1996, 353.

28 NUSSBAUM, 2011, p. 15.

29 KOZICKI; PUGLIESE, 2013, p. 323-324.

30 DWORKIN, 2013, p. 137. 
consensos, num contexto democrático, sobre questões como educação e sexualidade. Certamente, esta é uma área aonde se discute qual deve ser a relevância do discurso dos religiosos e das suas instituições no debate público, em especial nas esferas de tomada de decisão política (parlamentar) ejudicial.

Os dois trunfos do conceito dworkiniano de liberdade religiosa poderiam ser desenvolvidos aqui com mais propriedade. Todavia, diante da profusão de sua obra no Brasil, optou-se nesta pesquisa por apontar possíveis falhas de sua perspectiva. Como antes colocado, trata-se de uma simples ressalva, pois uma crítica mais profunda exigiria uma construção teórica, inclusive sobre um conceito de direito e justiça que, comparado à teoria de Dworkin, pudesse fornecer uma resposta alternativa a mais completa possível. Isto, porém, foge aos fins da presente pesquisa.

Como anteriormente mencionado, a limitação da religião pode acontecer, para Dworkin, com fins de proteção de direitos alheios, sendo que uma exceção só pode ser aberta a um grupo religioso caso também possa ser concedido a outros grupos. Ou seja, se uma determinada denominação pode fazer uso de alucinógenos, outros grupos com objetivos filosóficos, por exemplo, também poderiam ter a liberação. Uma exceção só pode ser concebida caso não se note uma violação a direitos essenciais de indivíduos ou grupos.

Para fins de problematização, imagine-se o seguinte caso: um ministro religioso cristão utiliza o púlpito para fazer pregações contra o casamento homoafetivo, utilizando textos bíblicos ${ }^{31}$ para reprovar tais fatos. Ao que tudo indica, esta fala estaria amparada pela liberdade religiosa, mesmo

31 Por exemplo, a carta de Paulo aos Romanos, Capítulo 1, verso 27, afirma que: "e, semelhantemente, também os homens, deixando o uso natural da mulher, se inflamaram em sua sensualidade uns para com os outros, homens com homens, cometendo torpeza e recebendo em si mesmos a recompensa que convinha ao seu erro" (BÍBLIA, 1999, p. 755). 
através da visão de Dworkin, já que o ministro possui independência ética para escolher quais princípios religiosos seguir $^{32}$. Por outro lado, a ressalva que se faz, em resumo, é que esta visão abrangente da liberdade religiosa não oferece mecanismos para frear uma irrazoável criminalização do discurso religioso, em especial aos ligados à interpretação do texto bíblico.

A abordagem de Dwokin, mesmo sem ser esta claramente sua intenção, pode ser utilizada nessa "guerra política" como forma de limitação da religião. Basta apenas que se levante a hipótese de que a expressão religiosa agride um direito, ou mesmo é tipificada como um ilícito penal. Especificamente no caso brasileiro, como se poderá conferir ao final do próximo tópico, ganha relevo a questão da criação do crime de homofobia. Não há, necessariamente, um inconveniente com a criação de um tipo penal. O desafio é que o texto penal não seja abrangente o suficiente para reprimir, por exemplo, o discurso bíblico acima exemplificado. Caso se chegue ao consenso de que o texto bíblico configura, em si, o ilícito de homofobia, a abordagem de Dworkin não oferece meios necessários para impedir tal proposta, já que a religião não precisa de justificativas especiais para limitá-la.

\section{RESSALVA AO CONCEITO DE LIBERDADE RELIGIOSA EM RELIGION WITHOUT GOD}

A ressalva ao conceito de liberdade religiosa em Religion Without God possui alguns argumentos subjacentes. $\mathrm{O}$ primeiro é que, apesar da vantagem prática para o aumento da expressão de minorias, a abordagem de religião dworkiniana é desmedida, pois alberga no conceito de religião 
aspectos que acabam menosprezando a ideia de "sagrado" e de "revelação da vontade divina" como elementos centrais na ética dos religiosos. O segundo, que decorre do primeiro, é que ela não é justa com as religiões que creem na revelação de um Deus pessoal através de um texto sagrado e também não parece ser a visão mais adequada para proteger a liberdade religiosa coletiva.

O primeiro argumento centra sua crítica na ideia de religião enquanto postura religiosa, através de algumas reflexões do filósofo do judaísmo Abraham Heschel ${ }^{33}$. Assim como Dworkin, Heschel tem como premissa o senso humano de "maravilhamento" (wonder) e "temor" (awe) como primeiro passo para compreensão da religiosidade. A diferença é que este estado de maravilhamento, em Heschel, não merece ainda a conceituação de religião. Isso porque tudo que existe no mundo e no universo não são pontos de partida para a ação de religação com essa beleza misteriosa, mas leva o humano a questionar, não a achar respostas. Afirma Heschel ${ }^{34}$ que "the sense of wonder, awe, and mystery is necessary, but not sufficient to find the way from wonder to worship, from willingness to realization, from awe to action" ${ }^{\prime 35}$.

Apesar de Dworkin buscar uma ligação entre a beleza do universo e a ação humana no Capítulo 2 de Religion Without God, a crença do ateísmo religioso não lembra atos de culto. Esse é um ponto central para a definição de religião: o conceito de religião pode ser colocado fora dos atos de religação, ou seja, do culto ao sagrado? Como afirmado, para fins de garantia da liberdade religiosa para minorias,

33 HESCHEL, 1955.

34 HESCHEL, 1955, p. 110.

35 Tradução livre: “A sensação de maravilhamento, admiração e mistério é necessária, mas não é suficiente para encontrar o caminho da maravilha ao culto, da disposição para a realização, do ato para a ação". 
é importante adotar a independência ética, como quer o autor, da liberdade religiosa. Por outro lado, é insuficiente elencar o ateísmo como religião sem o aspecto de culto ou de sacralidade. Que todos possuem independência ética não é algo que se possa discordar. Porém, ética e culto não são a mesma coisa, justamente pela figura da autoridade. $\mathrm{O}$ Estado, que exerce um papel também de autoridade, garante que qualquer membro de grupo religioso tenha o direito de saída, de deixar de ser membro, de um grupo ou seita religiosa onde, de alguma maneira, se exerce autoridade. Não há como desvincular, então, a religião da questão da existência, ou não, de uma autoridade da qual se tem um sentimento de débito, de dívida.

Não há que se discordar que o maravilhamento (wonder) é um pressuposto para a religiosidade, mas as religiões, inclusive com seus elementos inseparáveis de culto, começam a posteriori do maravilhamento ${ }^{36}$. A ideia de ritual ou culto só faz sentido com o elemento central do fenômeno religioso, ou seja, o sagrado ${ }^{37}$. O conhecimento religioso não é fruto do pensamento ou da imaginação quanto ao maravilhamento (wonder), mas de um encontro com o desconhecido. O sagrado é fruto de revelação de algo desconhecido, o que o distingue da ideia do profano. Para marcar esse elemento identificador da religião, é que Mircea Eliade propõe o nome de hierofania. Nesse sentido:

Poder-se-ia dizer que a história das religiões - desde as mais primitivas às mais elaboradas - é constituída por um número considerável de hierofanias, pelas manifestações das realidades sagradas. A partir da mais elementar hierofania - por exemplo, a manifestação do sagrado num objeto qualquer, urna pedra ou uma árvore - e até a hierofania suprema, que é, para um cristão,

36 HESCHEL, 1955, p. 112.

37 ELIADE, 1992. 
a encarnação de Deus em Jesus Cristo, não existe solução de continuidade. Encontramo-nos diante do mesmo ato misterioso: a manifestação de algo "de ordem diferente" - de uma realidade que não pertence ao nosso mundo - em objetos que fazem parte integrante do nosso mundo "natural", "profano" ${ }^{38}$.

O culto ao sagrado é justamente a diferença que se tem entre religião e magia, conforme sedimentado na antropo$\operatorname{logia}{ }^{39}$, uma vez que o ser humano percebe que seus ritos são ineficazes para controlar a natureza, que é justamente o objetivo da magia. O culto e o apego ao sagrado são elementos essenciais da religião. Sem tal crença na existência do sagrado (e do culto), não há que se falar em religião. $\mathrm{O}$ rito tem como consequência a existência de lugares sagrados (templos, igrejas, mesquitas, terreiros etc.), onde se encontram objetos sagrados. Estes, paradoxalmente, são elementos naturais (árvores, pedras, altares etc.), mas que evocam a revelação do sagrado, do desconhecido ${ }^{40}$.

O cerne da concepção religiosa de Dworkin é que a independência ética é livre de qualquer elemento externo, sagrado, desconhecido, que confira a veracidade de tal postura ética ${ }^{41}$. A possível comprovação ou não da existência de uma divindade seria irrelevante para a epistemologia moral e para o mundo dos valores. Acontece que, para as religiões, não há como desvincular a ética da autoridade sobre o sagrado. Não que os religiosos precisem comprovar cientificamente a existência da divindade para se vincular a qualquer movimento ou seita, mas é difícil compreender, como postula Dworkin, um conceito de religião tão amplo que se desvincule da existência da autoridade sobre questões sobre o sagrado.

\footnotetext{
38 ELIADE, 1992, p. 13.

39 GUERRA FILHO; CARNIO, 2013, p. 51-52.

40 GAARDER; HELLERN; NOTAKER, 2005, p. 28.

41 DOMINGO, 2013, p. 376.
} 
É evidente que, ao contrário do que postulava Locke $\mathrm{e}^{42}$, o ateísmo não significa uma postura que gere desconfiança ou que seja sinônimo de imoralidade. Mas este fato não pode levar à sentença dworkiniana de que a figura de Deus é irrelevante para a ideia de valor. A figura de Deus, como demonstra a construção filosófica de Dworkin, não é uma necessidade para se falar em objetividade dos valores. Por outro lado, não há como dizer absolutamente que tal objetividade não tem em Deus uma boa explicação. Em resumo, crer que Deus não é a explicação da objetividade dos valores não significa que Ele não o seja.

Tal ressalva, inclusive, poderia se basear numa linha jusnaturalista no sentido de demonstrar que a religião faz parte do conjunto de bens básicos naturais do ser humano ${ }^{43}$. Mas, como antes afirmado, não é possível aqui fazer uma crítica profunda sobre a visão completa de Dworkin sobre direito e moral ${ }^{44}$ a partir de outra construção concorrente, como o jusnaturalismo. Para não escapar ao enquadramento do marco teórico selecionado para o presente trabalho, é que se busca trazer outro autor liberal igualitário (John Rawls) para se realizar uma crítica interna a Dworkin, o que será objeto do próximo tópico da pesquisa. Antes, é preciso ingressar no segundo argumento que forma a presente ressalva, ou seja, a abordagem dworkiniana não é justa com as religiões que creem na revelação de um Deus pessoal através

\section{LOCKE, 1983.}

43 Como propõe, entre outros, John Finnis, especialmente no Capítulo IV, item G da obra Natural Law and Natural Rights (FINNIS, 2011).

44 Há quem sustente, como Carlos Alberto Simões de Tomaz e Roberto Correia da Silva Gomes, que diferentemente do que ocorre no positivismo, no visões como a de Dworkin apontam para uma cooriginarieade entre o Direito e a moral, que encontra locus privilegiado no ethos, ou seja, "nos costumes, na cotidianidade, onde o Direito deve ser arquitetonicamente pensado, elaborado, construído, sob o influxo de uma adequada compreensão" (TOMAZ; CALDAS, 2018, p. 161). 
de um texto sagrado e também não parece ser a visão mais adequada para proteger a liberdade religiosa coletiva.

Linda McLain ${ }^{45}$ aponta que a razão que guia a ética e o "viver bem" de um religioso é justamente obedecer ao texto sagrado. Entretanto, isso não significa, como no caso do cristianismo, que quem não observa a lei escrita de Deus não tem acesso à Sua vontade. No ponto de vista de um cristão, a moralidade, que tem na divindade seu ponto de origem, não se restringe a quem cultua ou observa o livro sagrado ${ }^{46}$. Isso pode ser observado do seguinte excerto paulino na carta aos Romanos, Capítulo 1, versos 18 ao 20:

Porque do céu se manifesta a ira de Deus sobre toda a impiedade e injustiça dos homens, que detêm a verdade em injustiça. Porquanto o que de Deus se pode conhecer neles se manifesta, porque Deus lho manifestou. Porque as suas coisas invisíveis, desde a criação do mundo, tanto o seu eterno poder, como a sua divindade, se entendem, e claramente se vêem pelas coisas que estão criadas, para que eles fiquem inescusáveis ${ }^{47}$.

As raízes históricas da Primeira Emenda da Constituição Norte-Americana e da Constituição Francesa pós-revolução apontam que as concepções mais recentes de igualdade e liberdade têm origem em disputas teológicas pós Reforma Protestante ${ }^{48}$. Nela, resumidamente, o que se

45 MCLAIN, 2014.

46 Utilizando a classificação tomista, pode-se afirmar que a revelação bíblica (lei divina) pode até não ser acessível a todos, mas a lei natural o é. Para uma leitura sobre a classificação das leis por Tomás de Aquino, cf. a obra "Questões de Tomás de Aquino sobre Direito e Política", de Michel Villey (2014), em especial o Capítulo 8.

47 BÍBLIA, 1999, p. 754.

48 Pode-se verificar uma análise histórica da influência de ideais protestantes na criação da Primeira Emenda da Constituição dos Estados Unidos na obra "The Religious Roots of The First Amendment" de Nicholas Miller (2012). Nela, Miller faz um percurso histórico para demonstrar a influência de ideais protestantes sobre algumas figuras essenciais na construção no 
discutia era o problema da autoridade para a interpretação dos textos bíblicos.

A necessidade de proteger os dissidentes e minoritários fez com que surgissem historicamente os textos legais que asseguram que a autoridade estatal garantiria o direito que Dworkin chama hoje de independência ética para que cada um pudesse decidir sobre questões de fé. Acontece que os textos legais que protegem a liberdade de consciência e crença não subsistirão caso não se preservem ou se criem entraves ao florescimento das religiões razoáveis, para usar uma linguagem rawlsiana. Ou seja, como aponta Rafael Domingo ${ }^{49}$, existe uma relação simbiótica e necessária entre religiões razoáveis e direito. Quando um interfere no outro, acaba causando a destruição de ambos.

O que se busca aqui é reforçar a ideia de que a religião, principalmente em seus ritos, não possa ser limitada sem justificativas imperiosas, por mais que Dworkin entenda que tal postura contrarie o tratamento igual entre crenças. Porém, sua abordagem acaba menosprezando matrizes religiosas que servem de base para a democracia, por comporem o que Rawls chama de família de doutrinas razoáveis. Ainda que se trate da limitação de religiões minoritárias que, para voltar no exemplo de Dworkin, utilizem alucinógeno como parte do seu culto, é preciso, mesmo nesses casos, que se exijam argumentos graves para sua limitação.

A expressão "independência ética" de Dworkin pode ser comparada à expressão "imperativo herético", cunhada

modelo norte-americano de separação entre Estado e Igreja, como James Madison. Tais ideais, mesmo de forma diversa, acabaram influenciando a ideia de laicidade francesa, como demonstra Georg Jellinek (1901) em pesquisa pioneira aonde aponta como os franceses beberam do ideário americano de neutralidade estatal. 
pelo sociólogo Peter Berger ${ }^{50}$. Para este, a Modernidade é marcada por uma mudança básica no que se trata da religiosidade. Na pré-Modernidade, geralmente os religiosos se achavam destinados a preservar uma determinada tradição religiosa. Quem questionava tal tradição era justamente um herege. Como aponta Berger, a palavra heresia vem do verbo grego hairein, que significa escolher. Uma hairesis, originalmente, significava apenas fazer uma escolha. Desta forma, herege era quem questionava tal tradição.

Com a Modernidade, a regra agora é o que Berger chama de imperativo herético, ou seja, "em matéria de religião, como de resto em outras áreas da vida e do pensamento humano, isso significa que o indivíduo moderno se defronta não apenas com a oportunidade, mas com a necessidade de fazer escolhas quanto a suas crenças" ${ }^{\prime \prime 1}$. Isso quer dizer que a heresia religiosa, que outrora era a atitude dos marginais e excêntricos, agora é a condição do humano que possui, na linguagem de Dworkin, independência ética.

Por mais que a democracia atual exija o imperativo herético, não se pode vindicar que o conceito de religião seja totalmente secularizado e reduzido à consciência. Por outro lado, Dworkin tem razão no sentido de não se poder utilizar a autoridade do direito para reforçar a autoridade de qualquer tradição religiosa. Mas isso não quer dizer que a religião seja um conceito desvinculado da ideia de autoridade.

O objetivo da presente ressalva, de forma prática, é que a separação dworkiniana entre parte científica e valorativa da religião, sendo que elas seriam independentes, não seja um entrave ao discurso religioso. Para o religioso, a existência da divindade enquanto autoridade moral (que Dworkin chama "parte científica da religião"), tem íntima relação com sua visão sobre os valores. É nesse sentido que se retorna ao

50 BERGER, 2017, p. 44.

51 BERGER, 2017, p. 48. 
que se apontou no primeiro tópico: a liberdade de expressão, apesar de ter uma justificativa deontológica, que protege a independência ética, também possui bases teleológicas, aqui, em especial, a busca pela verdade.

Uma leitura apressada de Religion Without God não deve resultar, por exemplo, na proibição da expressão de jusnaturalistas como Robert George e Patrick Lee, mesmo com o reconhecimento do casamento homoafetivo nos EUA, assim como no Brasil, que insistem em levar ao campo doutrinário jurídico o que consideram uma concepção verdadeira de casamento $^{52}$. Esta ressalva tem como ideal a preservação do direito à liberdade de expressão dos religiosos, apesar do reconhecimento de direitos às minorias LGBT's (Lésbicas, Gays, Bissexuais e Transexuais).

A última parte do segundo argumento para a presente ressalva à abordagem de Dworkin sobre a liberdade religiosa aponta que Religion Without God acaba protegendo principalmente a perspectiva individual, não a parte coletiva da religião.

O conceito de religião enquanto postura religiosa, como sustenta Dworkin, é muito amplo e desconectado de qualquer tradição, rito ou culto. Assim, acaba gerando problemas em outras esferas do tratamento da religião em sociedades democráticas, como a questão da imunidade tributária.

O desafio da definição do conceito de religião na esfera jurídica, jurisprudencial ou legal, é de grande dificuldade em países como os Estados Unidos da América, que possuem uma expressa cláusula de separação entre Estado e Igreja (Primeira Emenda). O mesmo ocorre no Brasil, nos termos do inciso I do artigo 19 da Constituição Federal ${ }^{53}$, ao estatuir que é vedado à União, aos Estados, ao Distrito Federal

52 LEE; GEORGE, 2014.

53 BRASIL, 1988. 
e aos Municípios "estabelecer cultos religiosos ou igrejas, subvencioná-los, embaraçar-lhes o funcionamento, ou manter com eles ou seus representantes relações de dependência ou aliança, ressalvada, na forma da lei, a colaboração de interesse público".

Esta cláusula de separação entre Estado e as religiões ganha especial relevo quando se envolve, entre outros aspectos, a questão econômica e tributária. Uma decorrência do dispositivo supracitado é que a Constituição Federal, em seu artigo 150, inciso VI, alínea $b$, veda que qualquer ente federativo possa instituir imposto ${ }^{54}$ sobre templos de qualquer culto, já que se busca criar um ambiente livre para o estabelecimento de atividade religiosa. É evidente que estipular o que seria culto religioso para fins de imunidade não parece ser a principal preocupação de uma abordagem mais ampla como a de Dworkin. Lidar com tal desafio é um efeito colateral de se levar a sério um conceito mais abrangente de religião. Quando se imagina questões envolvendo a proteção individual do religioso, realmente é salutar a perspectiva abrangente de Dworkin. O problema está na decorrência coletiva que, como se observa pelo menos no Brasil, tem efeitos econômicos.

Por tal justificativa é que a jurisprudência do Supremo Tribunal Federal acabou adotando um conceito de religião mais restrito quando, por exemplo, não reconheceu a imunidade tributária da Maçonaria ${ }^{55}$. Neste caso, alegou-se, entre outros pontos, já que o próprio sítio eletrônico da Grande Loja Maçonica do Estado do Rio Grande do Sul, que ingres-

54 Dois pontos importantes: primeiro, a imunidade se dá em relação à figura do imposto, não de outras espécies de tributo, como as taxas. Segundo, a imunidade não se destina somente ao templo, mas, como aponta a doutrina de Hugo de Brito Machado, se estende a todo o patrimônio necessário para sua manutenção (MACHADO, 2008, p. 286).

BRASIL, 2012a. 
sara com o Recurso, dizia expressamente que o grupo não era uma religião, bem como pelo caráter fechado e privado das reuniões, que não se poderia enquadrar a Maçonaria como religião para fins de imunidade tributária.

Quando se trata de reconhecer o direito de expressão de grupos minoritários, a perspectiva de Dworkin é bastante salutar. No exemplo da Maçonaria, esta poderia, caso estivesse sendo ameaçada em sua liberdade de expressão, exigir liberdade num mesmo sentido que um religioso quando solicita o não juramento à bandeira. $\mathrm{O}$ efeito colateral da perspectiva da liberdade religiosa enquanto independência ética, desprendida de tradições, é que não fornece meios para a aferição do que seria religião para fins do âmbito de fomento e parcerias entre o Estado e as denominações. Além da imunidade, as parcerias em serviços públicos como saúde, assistência social e educação, bem como a abertura para pregação religiosa em casas de internação coletiva, entre outros pontos, necessitam de uma definição mais específica do conceito de religião.

As críticas feitas até aqui podem dar a impressão de que se postula que a base filosófica-política jusnaturalista com fins comunitaristas é superior à concepção de direito e ao liberalismo dworkiniano. O próximo tópico visa demonstrar que, ao contrário do que tal impressão aponta, as críticas feitas por este trabalho a Dworkin podem emanar de uma construção liberal, como a de John Rawls. Não é necessário que se aproprie do jusnaturalismo para perceber as limitações do conceito de liberdade religiosa de Dworkin. 


\section{RAWLS VERSUS DWORKIN: A PRIORIDADE DA LIBERDADE RELIGIOSA}

A ligação entre John Rawls e Ronald Dworkin não é somente apontada por comentadores como Gargarella ${ }^{56}$, mas também pelos próprios autores. A título de exemplo, na obra A Justiça de Toga, Dworkin ${ }^{57}$ dedica um capítulo inteiro à análise da teoria de Rawls, apontando similitudes e distinções, especialmente na compreensão do direito.

A Teoria da Justiça de Rawls é conhecida por propor um modelo de construção política liberal mediada por princípios de justiça. Para tanto, o autor lança mão de recursos filosóficos como os da "posição original" e do "véu da ignorância", além dos "dois princípios de justiça". Por questões do limite de espaço de discussão da presente pesquisa, não se pode abordar profundamente tais conceitos. De forma rudimentar, a "posição original" é o princípio racional que inicia a proposta neocontratualista apresentada por Rawls, pelo qual pessoas razoáveis chegariam aos dois princípios da justiça, que integram o conceito de "justiça como equidade"

56 GARGARELA, 2008.

57 DWORKIN, 2010, p. 341- 369.

58 O primeiro princípio estabelece a prioridade da liberdade: "each person is to have an equal right to the most extensive scheme of equal basic liberties compatible with a similar scheme of liberties for others" (RAWLS, 1999, p. 53). Tradução: "cada pessoa deve ter um direito igual ao sistema mais extenso de iguais liberdades fundamentais que seja compatível com um sistema similar de liberdades para as outras pessoas" (RAWLS, 2008, p. 73). Já o segundo princípio (também conhecido como o "princípio da diferença") ressalta em que condições podem-se ter desigualdades entre cidadãos, mas sem agressão à Justiça: "Social and economic inequalities are to be arranged so that they are both (a) to the greatest expected benefit of the least advantaged and (b) attached to offices and positions open to all under conditions of fair equality of opportunity" (RAWLS, 1999, p. 73). Tradução: "as desigualdades sociais e econômicas devem estar dispostas 
Estes seriam escolhidos para conformar a estrutura básica da sociedade em detrimento dos princípios utilitaristas ou perfeccionistas.

Para que se escolham os princípios de justiça de forma legítima e democrática, é preciso que as partes não saibam qual é a sua posição nessa comunidade, o que Rawls chama de "véu da ignorância". Isto é, somente quando as partes não são guiadas por suas posições na sociedade, ou por seus dotes naturais, ou por qualquer outra característica específica de uma determinada sociedade, é que podem razoavelmente propor princípios de justiça aceitos por todos ${ }^{59}$.

Feita essa breve explanação, pode-se entender que, a princípio, Rawls concordaria com Dworkin sobre os limites de proteção e a natureza democrática da liberdade religiosa. Como sob o véu da ignorância não se pode colocar determinadas religiões acima de outras, os contratos sociais (inclusive a própria Constituição) não podem prever tratamento privilegiado a determinadas religiões sobre as outras. Tal argumento poderia ter fundamento caso a teoria rawlsiana se restringisse aos conceitos colocados acima. Embora Rawls tenha se notabilizado por tais conceitos, não se pode perder de vista que a posição original é somente o primeiro estágio do neocontratualismo rawlsiano.

Não se pode tratar de assuntos como a decisão judicial em determinados casos ou políticas públicas sobre qualquer assunto utilizando-se de ideias como a posição original e o véu da ignorância de forma aleatória. Tal ressalva é feita pelo próprio autor, quando afirma: ${ }^{60}$ "It is essential to keep

de tal modo que tanto (a) propiciem o máximo benefício esperado para os menos favorecidos como (b) estejam vinculadas a cargos e posições abertos a todos em condições de igualdade equitativa de oportunidades" (RAWLS, 2008, p. 100).

59 RAWLS, 1999, p. 212.

60 RAWLS, 1999, p. 176. 
in mind that the four-stage sequence is a device for applying the principles of justice. This scheme is part of the theory of justice as fairness and not an account of how constitutional conventions and legislatures actually proceed ${ }^{61 "}$.

$\mathrm{O}$ argumento da posição original se desdobra em quatro estágios. Em cada etapa, o véu se torna cada vez menos presente. No § 31 da Theory of Justice, Rawls ${ }^{62}$ explica as quatro etapas de seu argumento. Na primeira, que se pode pensar como uma posição original em sentido estrito, os princípios da justiça são escolhidos e há uma forte incidência do véu da ignorância no sentido de não se conhecer circunstâncias pessoais e sociais, a não ser noções sobre liberdade de consciência e de reciprocidade. Na segunda, há uma convenção constitucional, aonde se estabelecem os princípios e regras básicas de criação legislativa e direitos fundamentais. Na terceira, são escolhidos os princípios de regulação econômica e de políticas públicas. A quarta etapa se dá quando os órgãos públicos executam tais políticas e julgam casos concretos. Nas últimas três últimas etapas, o véu é levantado um pouco mais a cada estágio, isto é, sempre se necessita de mais informações sobre circunstâncias da realidade política e social para se avançar nas etapas ${ }^{63}$.

61 Tradução: “É essencial ter em mente que a sequência de quatro estágios é um recurso para a aplicação dos princípios de justiça. Esse esquema faz parte da teoria da justiça como equidade, e não uma explanação de como as convenções constitucionais e as legislaturas procedem na prática" (RAWLS, 2008, p. 246.)

62 RAWLS, 1999, p. 171-176.

63 Como sistematiza Frank Lovett (2013, p. 96-97), “a primeira etapa é a própria posição original: neste estágio, as pessoas selecionam os princípios básicos que servirão como a manifestação pública da justiça social para a sua sociedade, e elas fazem essa seleção de trás de um véu de ignorância que exclui qualquer conhecimento de suas características pessoais ou de circunstâncias particulares de sua sociedade. A segunda etapa corresponde a uma convenção constitucional na qual as pessoas projetam um sistema de governo e a lei constitucional para a sua 
Compreender tal estrutura da proposta rawlsiana faz com que não se presuma que Rawls e Dworkin possuem a mesma visão sobre a liberdade religiosa. Adrew Koppelman, percebendo a imprudência de tal argumento, afirma que a ideia de que Rawls apoiaria que a religião não teria status de proteção especial acaba sendo um erro de interpretação, e aponta que, ao contrário do que se pode pensar, a teoria rawlsiana apoia o regime americano de proteção especial das religiões, como consta no Religious Freedom Restoration Act ${ }^{64}$ :

Liberty of conscience can't be implemented without reliance on contestable values such as religion. Public reason, when refracted through the four-stage sequence (where it becomes less constraining at each stage of the sequence), is far less exclusionary than the proponents of liberal neutrality hope. Fulfilling the commitments made in the original position, for people in the world here and now, requires taking account of the values that those people hold. A Rawlsian position thus can support the American regime of religious accommodation ${ }^{65}$.

sociedade, usando os princípios selecionados na primeira etapa como guia. (...) Uma vez estabelecidos um sistema de governo e uma lei constitucional, entramos na terceira fase, correspondente ao processo de definição de políticas públicas e de regulamentações socioeconômicas. É nesta fase, de acordo com Rawls, que o segundo princípio da justiça como equidade - igualdade justa de oportunidades e princípio da diferença - seria implementado. (...) O quarto e último estágio é a fase em que os órgãos públicos, o sistema de justiça e os cidadãos comuns respeitam as instituições e levam a cabo as políticas adotadas nos últimos dois estágios. Nesta etapa, é claro, não há véu da ignorância: todo mundo sabe exatamente quem é e quais as circunstâncias da situação particular em que estão".

64 KOPPELMAN, 2017, p. 31-32.

65 Tradução livre: "A liberdade de consciência não pode ser implementada sem depender de valores contestáveis como a religião. A razão pública, quando refratada através da sequência em quatro estágios (onde se torna menos constrangedor em cada etapa da sequência), é muito menos excludente do que os defensores da neutralidade liberal esperam. Cumprir os compromissos assumidos na posição original, para as pessoas no mundo aqui e agora, exige ter em conta os valores que essas 
Focando na etapa da convenção constitucional, Rawls aponta que as partes conhecem os fatos gerais relevantes sobre sua sociedade, ou seja, seus recursos naturais, seu nível de avanço econômico e cultura política e, por que não, elementos de formação religiosa ${ }^{66}$, mesmo que não se saiba pessoalmente qual é sua posição social ou visão religiosa. Como aponta Koppelman ${ }^{67}$, as partes, na fase constitucional, sabem quais as formas de crença e conduta, numa cultura, mais valorizadas pelos nativos, até para garantir termos de equidade entre as doutrinas. Segundo o autor, a sociedade norte-americana possui muitos grupos religiosos, e não existe uma maioria esmagadora em termos de uma denominação prevalente. Portanto, aumenta-se a chance de se criar meios para frear possíveis opressões governamentais, sendo plenamente possível a adoção de leis como a Religious Freedom Restoration Act.

Para esclarecer a matriz religiosa da sociedade norte-americana, contexto social aonde Religion Without God se insere, ganha relevância a recente pesquisa dos sociólogos Timothy L. O'Brien e Shiri Noy ${ }^{68}$ sobre a relação entre a religião e a ciência naquele País.

pessoas possuem. Uma posição rawlsiana assim pode apoiar o regime americano de acomodação religiosa".

66 É preciso que se reitere que as etapas da posição original não são uma reprodução histórica de uma experiência específica, mas se trata de uma visão normativa social. No caso brasileiro, pode-se avaliar que o exercício do véu da ignorância na fase constitucional teria um efeito de contenção da extensão do texto constitucional. Por buscar resolver diversas situações que caberiam estar nos próximos estágios (em especial a parte de políticas públicas e questões econômicas), a Constituição Federal de 88 acabou se tornando o que a doutrina chama de uma Carta prolixa (SOUZA NETO; SARMENTO, 2014).

67 KOPPELMAN, 2017, p. 34-35.

68 O'BRIEN; NOY, 2015. 
Nessa pesquisa de âmbito nacional ficou notória a existência de três grupos: os tradicionais (43\%), que são aqueles que preferem adotar uma visão religiosa da vida em detrimento da ciência como parâmetro para questões políticas delicadas; os modernos (36\%), que possuem a visão oposta aos tradicionais; e os pós-seculares $(21 \%)$, que são os que entendem ser possível um alinhamento entre o pensamento religioso e científico.

Sobre questões como a teoria do big bang, aborto, eutanásia, alimento transgênico, as respostas da pesquisa demonstram, mesmo sem fazer menção a denominações específicas, que a fé, assim como a ciência, molda a visão do cidadão norte-americano sobre a política. Independentemente da avaliação que se tenha, este é um fato que não pode ser escondido no segundo estágio da posição original. O que chamou atenção na pesquisa é que a religião tem um papel profundo e difuso na formação do cidadão, inclusive naqueles que dizem não pertencer a nenhuma denominação, como muitos que foram considerados como pós-seculares ${ }^{69}$.

No caso brasileiro, $92 \%$ da população afirma pertencer a alguma denominação religiosa ${ }^{70}$. Deste percentual, a grande maioria se denomina pertencer a uma doutrina cristã. Ao se apontar tais estatísticas, não se pleiteia aqui que deva existir uma submissão da política democrática à autoridade religiosa, em especial às denominações cristãs. Por outro lado, o que se sustenta é que não se possa limitar a expressão religiosa em si, em nível constitucional ou posterior, sem que haja um forte argumento para tanto. A prioridade da liberdade religiosa se dá quando esta se manifesta enquanto tradição. Tal prioridade não pode significar, entretanto, que a expressão religiosa sobre quaisquer assuntos, principalmente os externos à crença, guardem algum tipo de intocabilidade.

69 O'BRIEN; NOY, 2015, p. 111.

70 BRASIL, 2012b. 
Rawls não chega a definir expressamente que a religião possui prioridade em sua proteção. Porém, a leitura de sua obra, principalmente a abordagem da posição original em quatro etapas, é compatível com textos legais que visam proteger os grupos religiosos de intervenções indevidas, sem graves justificativas. Contrariamente ao sustentado por Dworkin em Religion Without God, a parte da religião que chama de "científica" necessita de proteção especial assim como a parte correspondente à independência ética.

\section{CONCLUSÃO}

Ronald Dworkin é um autor com grande notoriedade no meio acadêmico e na jurisprudência brasileira. Bem ou mal aplicados, seus conceitos são propagados e utilizados, em especial quando se trata da proteção aos direitos fundamentais. A presente pesquisa teve como objetivo apresentar sua visão sobre a liberdade religiosa, em especial na obra Religion Without God.

Dworkin apoia uma percepção mais abrangente do conceito de religião, como o próprio título da obra indica, assemelhando a prática religiosa a uma atitude (religious attitude), o que vai além dos ritos religiosos convencionais, englobando o que ele chama de ateísmo religioso.

Quando se toma a liberdade religiosa numa perspectiva de expressão religiosa, de aceitação de práticas pelo poder estatal, a perspectiva de Dworkin fornece elementos de defesa de minorias religiosas, pois seu conceito abrangente iguala qualquer atitude religiosa às agremiações tradicionais, trazendo dignidade a qualquer manifestação, desde que não agrida direitos fundamentais.

Por outro lado, buscou-se evidenciar alguns problemas ao se conceituar a religião de forma totalmente secularizada 
e reduzida à consciência. O primeiro "efeito colateral" é que tal postura abrangente não fornece meios para a aferição do que seria religião para fins do âmbito de fomento e parcerias entre o Estado e as instituições. Não se trata mais de reconhecimento de práticas singulares, mas de decorrências da concepção coletiva da religião, como, p. ex., o financiamento público de ações das religiões. Para que isso ocorra, é preciso elementos mais objetivos e históricos do conceito de religião.

O segundo efeito colateral é que, para Dworkin, a liberdade das religiões já constituídas não deve ter qualquer tratamento diferenciado em relação aos demais direitos fundamentais. Não é que se discorde totalmente desta assertiva, porém não se pode apagar a história e cultura de um povo, inclusive a história religiosa, com base em argumentos com baixa carga argumentativa.

O que se pretende é atenuar a proposta de Dworkin neste ponto, no sentido de que, apesar de não serem intocáveis, as religiões tradicionais que formam a cultura de um povo devem ter um mínimo de prioridade. Isso porque, ao se limitar a expressão de uma crença tradicional, exige-se uma forte carga argumentativa no sentido da insubsistência da prática religiosa diante de outros direitos fundamentais e das bases democráticas. Um problema da abordagem dworkiniana é que esta não lida com a possibilidade de criminalização indevida do discurso de religiões mais tradicionais, com a justificativa de se proteger minorias sexuais, por exemplo.

Não se quer aqui propor que a autoridade dos ministros religiosos deva ser intocável, ou mesmo que as tradições devam sempre prevalecer em relação a direitos alheios. Diversas tradições históricas são execráveis, como a escravidão, que por vezes foi apoiada por autoridades religiosas. $\mathrm{O}$ intuito da ressalva apresentada é apontar que a liberdade religiosa deve, de um lado, ser ampla o suficiente para ga- 
rantir a não-discriminação de minorias, como quer Dworkin, mas não se pode, como consequência, permitir que não se exijam argumentos qualificados o suficiente para a limitação dos ritos e cultos religiosos.

Em síntese, conclui-se que restou demonstrada a hipótese inicial, no sentido de que a concepção de liberdade religiosa objeto da obra Religião Sem Deus, de Ronald Dworkin, embora bastante abrangente, incluindo-se como seus titulares ateus e agnósticos, é insuficiente para explicar diversas questões sobre o tema da religião no âmbito de uma democracia.

\section{REFERÊNCIAS}

BERGER, Peter L. O imperativo herético: possibilidades contemporâneas da afirmação religiosa. Flávio Gordon (Trad). Petrópolis: Editora Vozes, 2017.

BÍBLIA. Novo Testamento. Romanos. In: Bíblia Sagrada: contendo o antigo e o novo testamento. João Ferreira de Almeida (Trad). Barueri: Sociedade Bíblica do Brasil, 1999.

BORGES, Alexandre Walmott; ALVES, Rubens Valtecides. O Estado laico e a liberdade religiosa na experiência constitucional brasileira. Revista Brasileira de Estudos Políticos, Belo Horizonte, n. 107, p. 227-265, jul./dez. 2013.

BRASIL. Constituição da República Federativa do Brasil de 1988. Disponível em: >. Acesso em 8 maio 2019.

BRASIL. IBGE. Censo demográfico 2010. Características gerais da população, religião e pessoas com deficiência. Rio de Janeiro: IBGE, 2012b. Disponível em: <https://goo.gl/ ojhGo2>. Acesso em: 20 nov. 2018.

BRASIL. Supremo Tribunal Federal. Recurso Extraordinário n. 562.351/RS. Relator Ministro Ricardo Lewandowski. 
Brasília: Diário da Justiça, 14 dez. 2012a. Disponível em: <https://goo.gl/zYaDac>. Acesso em: 8 dez. 2018.

DOMINGO, Rafael. Religion for Hedgehogs? An argument against the dworkinian approach to religious freedom. Oxford Journal of Law and Religion, v. 2, n. 2, p. 371-392, 2013. Disponível em: < https://ssrn.com/abstract=2209539>. Acesso em: 20 jul. 2018.

DWORKIN, Ronald. A justiça de toga. Jefferson Luiz Camargo (Trad). São Paulo: WMF Martins Fontes, 2010.

DWORKIN, Ronald. A raposa e o porco espinho: justiça e valor. Marcelo Brandão Cipolla (Trad). São Paulo: WMF Martins Fontes, 2014.

DWORKIN, Ronald. Domínio da vida: Aborto, eutanásia e liberdades individuais. Jefferson Luiz Camargo (Trad). São Paulo: WMF Martins Fontes, 2009.

DWORKIN, Ronald. Is democracy possible here? Principles for a new political debate. Princeton: Princeton University Press, 2006.

DWORKIN, Ronald. Justice for hedgehogs. Cambridge: The Belknap Press of Havard University Press, 2011.

DWORKIN, Ronald. Life's dominion: an argument about abortion, eutanásia, and individual freedom. New York: Vintage Books Edition, 1993.

DWORKIN, Ronald. Religion without god. Cambridge: Havard University Press, 2013.

ELIADE, Mircea. O sagrado e o profano. Rogério Fernandes (Trad). São Paulo: Martins Fontes, 1992.

FINNIS, John. Natural law and natural rights. Oxford: Oxford University Press, 2011. 
FIORILLO, Celso Antonio Pacheco; FERREIRA, Renata Marques. Transmissão de conhecimentos religiosos na sociedade da informação e sua tutela jurídica em face do direito ambiental constitucional. R. Opin. Jur., Fortaleza, ano 16, n. 22, p. 38-55, jan./jun. 2018.

GAARDER, Jostein; HELLERN, Victor; NOTAKER, Henry.

O livro das religiões. Isa Mara Lando (Trad). São Paulo: Compahia das Letras, 2005.

GARGARELLA, Roberto. As teorias da justiça depois de Rawls: um breve manual de Filosofia Política. Alonso Reis Freire (Trad). São Paulo: WMF Martins Fontes, 2008.

GUERRA FILHO, Willis Santiago; CARNIO, Henrique Gaberlini. Teoria política do direito: a expansão política do direito. 2. ed. São Paulo: Revista dos Tribunais. 2013.

HESCHEL, Abraham Joshua. God in search of man: a philosophy of judaism. Nova Iorque: Harper \& Row Publishers, 1955.

JELLINEK, Georg. The declaration of the rights of man and of citizens: A contribution to modern constitutional history. Max Farrand (Trad). Nova Iorque: Henry Holt and Co., 1901. Disponível em: <http://oll.libertyfund.org/titles/1176>. Acesso em: 12 dez. 2017.

KOPPELMAN, Andrew. A rawlsian defence of special treatment for religion. In: LABORDE, Cécile; BARDON, Aurélia (Ed). Religion in liberal political philosophy. Oxford: Oxford University Press, 2017.

KOZICKI, Katya; PUGLIESE, William Soares. Religião sem Deus: uma questão de fé e valores. Revista Direito e Práxis, Rio de Janeiro, v. 4, n. 2, p. 319-342, 2013.

LEE, Patrick; GEORGE, Robert P. Conjugal union: what marriage is and why it matters. Oxford: Oxford University Press, 2014. 
LEITER, Brian. Why tolerate religion? Princeton: Princeton University Press, 2013.

LOCKE, John. Carta acerca da tolerância. Anoar Aiex (Trad). São Paulo: Abril Cultural, 1983.

LOVETT, Frank. Uma teoria da justiça de John Rawls: guia de leitura. Vinícius Figueira (Trad). Porto Alegre: Penso, 2013.

MACEDO JUNIOR, Ronaldo Porto. Ronald Dworkin: teórico do direito. In: CAMPILONGO, Celso Fernandes; GONZAGA, Alvaro de Azevedo; FREIRE, André Luiz (Coords.). Enciclopédia jurídica da PUC-SP. Tomo: Teoria Geral e Filosofia do Direito. São Paulo: Pontifícia Universidade Católica de São Paulo, 2017. Disponível em: <https://goo. gl/jz5Zkp>. Acesso em: 7 nov. 2017.

MACHADO, Hugo de Brito. Curso de direito tributário. 29. ed. São Paulo: Malheiros, 2008.

MACHADO, Jónatas Eduardo Mendes. Liberdade religiosa numa comunidade constitucional inclusiva. Coimbra: Coimbra Editora, 1996.

MCCLAIN, Linda C. Can religion without god lead to religious liberty without conflict? In: Boston University Law Review 1273, ano 2014; Boston Univ. School of Law, Public Law Research Paper No. 14-45. Disponível em: <https:// ssrn.com/abstract=2472081>. Acesso em: 6 nov. 2017.

MILLER, Nicholas. The religious roots of the first amendment: dissenting protestants and the separation of church and state. Oxford: Oxford University Press, 2012.

NUSSBAUM, Martha C. Libertad de conciencia: el ataque a la igualdad de respeto. Patrícia Soley-Beltran (Trad). Madri: Katz Editores, 2011. 
O'BRIEN, Timothy; NOY, Shiri. Traditional, Modern, and Post-Secular Perspectives on Science and Religion in the United States. In: American Sociological Review, Vol. 80(1) 92-115, 2015. Disponível em: < https://goo.gl/6R7Wbp>. Acesso em: 22 nov. 2017.

RAWLS, John. A theory of justice. Cambridge: The Belknap Press of Havard University Press, 1999.

RAWLS, John. Uma teoria da justiça. Jussara Simões (Trad). São Paulo: Martins Fontes, 2008.

SOUZA NETO, Cláudio Pereira; SARMENTO, Daniel. Direito constitucional: teoria, história e métodos de trabalho. Belo Horizonte: Editora Fórum, 2014.

TOMAZ, Carlos Alberto Simões de; CALDAS, Roberto Correia da Silva Gomes. A cooriginariedade entre Direito e moral, e a conformação da moralidade administrativa no sistema jurídico brasileiro. Revista Brasileira de Estudos Políticos, Belo Horizonte, n. 117, p. 159-191, jul./dez. 2018. VILLEY, Michel. Questões de Tomás de Aquino sobre direito e política. Ivone Benedetti (Trad). São Paulo: WMF Martins Fontes, 2014. 
O texto foi fruto de pesquisa realizada pelo autor Dilson Cavalcanti durante seus estudos no Doutorado em Direito. Ao se trabalhar o direito à liberdade de expressão religiosa a partir de John Rawls, o autor se deparou com o conceito, ainda sem maiores análises no Brasil, de Ronald Dworkin na obra Religion Without God . Sendo assim, a concepção e desenho da pesquisa e coleta e processamento dos dados foram feitas pelo primeiro autor, Professor Dilson Cavalcanti.

Já a análise e interpretação dos dados, especificamente sobre a clareza e ligação dos dados levantados com o formato editorial da RBEP, bem como a redação dos elementos como conclusões, introdução, resumo, revisão final do texto foi realizada pelo co-autor Professor José Antonio Remédio. (Texto informado pelos autores)

Recebido em 09/05/2019

Aprovado em 19/09/2019

Dilson Cavalcanti Batista Neto

E-mail: dilson.neto@unasp.edu.br

José Antonio Remédio

E-mail: jaremedio@yahoo.com.br 